\title{
Silvio Santos no rádio: uma história a ser contada ${ }^{1}$
}

\author{
Rafael Barbosa Fialho MARTINS ${ }^{2}$
}

\begin{abstract}
Resumo:
$\mathrm{O}$ artigo pretende dar os primeiros passos rumo a uma reconstrução histórica acerca da atuação do apresentador Silvio Santos no meio radiofônico brasileiro, já que, apesar da (re)conhecida relevância do animador na televisão, ainda são raras as iniciativas sobre sua profícua trajetória em emissoras de rádio. Nosso objetivo é indicar bases para futuras investigações sobre o tema, e, para isso, realizamos uma análise documental dos desdobramentos dos programas e da trajetória de Silvio. Acredita-se que, com uma pesquisa focada nas raízes orais dos tempos de Silvio Santos no rádio, serão oferecidos mais subsídios para a compreensão de sua complexa figura, caracterizada por uma incomum expressividade midiática ainda nos dias de hoje.
\end{abstract}

Palavras-chave: Silvio Santos. Rádio. História do rádio.

\section{Silvio Santos on the radio: a story to be told}

\begin{abstract}
:
This article intends to take the first steps towards a historical reconstruction about the role of TV host Silvio Santos in the Brazilian radio medium. Despite him known relevance in television, the initiatives on his profession trajectory in broadcasters of radio are still rare. Our objective is to provide a basis for future research about this subject, and for this, we do a documentary analysis of the program developments and the professional history of Silvio. It is believed that with a research focused on the oral roots of the times of Silvio Santos on the radio, more subsidies will be offered for an understanding of its complex figure, characterized by an unusual expressiveness mediatic still today.
\end{abstract}

Keywords: Silvio Santos. Radio. History of the radio.

\section{Silvio Santos en la radio: una historia para ser contada}

\section{Resumen:}

El artículo tiene la intención de dar los primeros pasos hacia una reconstrucción histórica sobre la actuación del presentador Silvio Santos para la radio brasileña, ya que, a pesar de la (re)conocida relevancia del animador en la televisión, todavía son raras las iniciativas en su prolífica carrera en la radiodifusión. Nuestro objetivo es indicar las bases para futuras investigaciones sobre el tema, y para ello, se realizó un análisis documental de las consecuencias de los programas y la trayectoria de Silvio. Se cree que con una investigación centrada en las raíces orales de Silvio Santos en los tiempos de radio, se ofrecerá más apoyo para la comprensión de su figura compleja, caracterizada por una inusual expresividad mediática aún en los días actuales.

Palabras clave: Silvio Santos. Radio. Historia de la radio.

\section{INTRODUÇÃO}

"Maior apresentador do Brasil"; "O dono dos domingos"; "Lenda viva da televisão brasileira": esses são alguns dos títulos conferidos a Silvio Santos, conhecido principalmente por seu trabalho em TV. Tais elogios negligenciam, porém, uma

\footnotetext{
${ }^{1}$ Uma versão preliminar deste artigo foi apresentada no V Encontro de Pesquisa em História, em 2016, na Universidade Federal de Minas Gerais, em Belo Horizonte, sem publicação em anais.

${ }^{2}$ Doutorando em Comunicação Social pela Universidade Federal de Minas Gerais. Mestre em Comunicação Social pela mesma instituição. Jornalista pela Universidade Federal de Viçosa. E-mail: rafaelbfialho@gmail.com.
} 
importante fase da trajetória do comunicador de massa, que iniciou suas atividades no rádio para depois se inserir no mercado televisivo.

Acreditamos que estudar a faceta radiofônica desse personagem nos ajuda a compreender melhor o fenômeno comunicativo que se formou ao seu redor - afinal, foi nos programas de rádio que Silvio consolidou o estilo de apresentação que posteriormente o consagrou como um dos mais reconhecidos profissionais de televisão - e também nos oferece melhores condições de entendermos a trajetória do rádio no contexto em que o apresentador esteve presente. Contudo, assumimos o caráter experimental e indiciário de nosso trabalho, considerando-o como um primeiro passo. Nosso objetivo é lançar bases para futuras investigações sobre Silvio Santos no rádio a partir de uma reunião de pistas históricas do referido tema.

\section{Sobre metodologia}

Encontrar uma metodologia adequada para um objeto de pesquisa praticamente inexplorado coloca-se como um dos desafios que tal empreendimento demanda, afinal, o pesquisador que está nesse tipo de situação é constantemente incomodado pela pergunta: qual abordagem utilizar para um tema ainda pouco estudado?

Por ora, a análise documental parece-nos ser a saída mais viável e pertinente para os interesses investigativos, concentrados em um primeiro mapeamento e estado da arte do corpus. Assim, neste trabalho, tomamos a análise documental como método e também, especialmente, como técnica. Sonia Moreira (2004, p. 272) explica essa dupla função da metodologia escolhida, que pode ser considerada "método porque pressupõe o ângulo escolhido como base de uma investigação. Técnica porque é um recurso que complementa outras formas de obtenção de dados, como a entrevista e o questionário".

Compreendida como a identificação, verificação e apreciação de documentos para objetivos específicos, seu uso mais comum se dá em pesquisas sobre o resgate histórico dos meios, de personagens ou de períodos. Não por acaso, dois exemplos trazidos por Moreira (2004) tratam de estudos sobre o rádio numa perspectiva histórica, assim como o presente artigo. A análise documental é realizada a partir de semelhanças e diferenças, em um modo de investigação baseado em um conjunto de operações intelectuais que objetivam descrever e representar os documentos, sistematizando-os e facilitando sua recuperação (MOREIRA, 2004).

Em nosso caso, a busca e sistematização ocorreram em duas frentes: i) revisão 
bibliográfica e biográfica de Silvio como locutor de rádio e ii) pesquisa em revistas especializadas da época. Também recorremos a trechos de seus programas como material complementar para nossa reflexão. A autora afirma que esse tipo de análise frequentemente é de origem secundária, já que tanto a coleta quanto a análise do material recolhido são feitas com base em "[...] conhecimento, dados ou informação já reunidos ou organizados" (MOREIRA, 2004, p. 272).

Esse é o caso de nosso estudo, que reúne e analisa material previamente produzido sobre o objeto de pesquisa em tela: nosso corpus se constitui em três biografias (CHIARI, 2001; SILVA, 2000; SILVA, 1972); uma dissertação de mestrado (LOPES, 1982); uma matéria publicada em revistas (CAMINHA, 1969) e um artigo proveniente de um site (MORGADO, 2011). Mesmo os trechos originais dos programas utilizados como material complementar são de ordem secundária, já que são partes editadas e posteriormente disponibilizadas na internet.

Apesar das desvantagens apontadas por Moreira (2004) em relação a esse tipo de fonte - risco de dados imprecisos ou limitados -, acreditamos no potencial do material coletado, se considerarmos que este é um primeiro esforço para estimular a pesquisa sobre a contribuição de Silvio Santos para o rádio e vice-versa. A perspectiva adotada em nosso trabalho é qualitativa, já que se detém sobre o teor, o conteúdo do material selecionado como corpus.

\section{Revirando o baú de Silvio Santos}

As fontes de informação mais comuns a respeito da trajetória de Senor Abravanel (nome verdadeiro do apresentador) são suas biografias. A primeira delas, $A$ vida espetacular de Silvio Santos, lançada em 1972 pela editora L'Oren, é, na verdade, um compilado da série especial que o jornalista Arlindo Silva escrevera para a revista $O$ Cruzeiro no mesmo ano. Em um tom elogioso e enaltecedor, Arlindo reconta a vida de Silvio segundo uma série de entrevistas com o apresentador. A celebração da trajetória de sorte repete-se nas outras duas publicações biográficas: A fantástica história de Silvio Santos (2000), uma reedição atualizada do primeiro livro de Arlindo, agora pela Editora do Brasil, e Silvio Santos, a história de um vencedor (2001), especial editado pela revista Contigo! no ensejo do sequestro do animador, ocorrido em 2001. 
De forma geral, a história do "dono do Baú"3 é reverenciada e referenciada como um exemplo de sucesso a ser seguido por todos os brasileiros. A ascensão de vendedor de rua a empresário ganha tons de contos de fada e lança mão de valores como sorte, trabalho e destino. Sua vida já foi tema de publicações em numerosas revistas, reportagens em jornais e emissoras de televisão, vídeos na internet, documentários, trabalhos de conclusão de curso em Comunicação e samba enredo de carnaval. Por isso, nos furtaremos a descrever novamente tal história, tarefa já exaustivamente realizada pelas iniciativas citadas anteriormente. Interessa-nos, ao contrário, descortinar um dos capítulos menos explorados, privilegiando os aspectos que dizem respeito ao envolvimento de Silvio com o rádio. Recorremos, então, a essas narrativas biográficas na busca por vestígios a respeito da "história sonora" de Silvio Santos.

É possível perceber que a estratégia de mitificação é utilizada também para contar a fase de atuação de Silvio no rádio, narrada como uma série de acasos e descaminhos próprios de um mito. Silva $(2000 ; 1972)$ enumera as qualidades de Silvio como camelô, destacando seu poder de persuasão e comunicação, e lembra que, não poucas vezes, o jovem vendedor de bugigangas na rua era pego pelos fiscais da Prefeitura do Rio de Janeiro por exercer tal atividade, sempre se esquivando ou recomeçando. Em uma dessas ocasiões, teria ocorrido o improvável, já que o diretor de fiscalização da Prefeitura, ao invés de prendê-lo, encaminhou-o para uma rádio, como Silvio mesmo conta:

Mas quando ele me viu trabalhando, viu que eu tinha muito pouca idade, viu que eu falava regularmente, viu que eu era estudante, modificou seu pensamento a meu respeito. Ao invés de me levar para o Juizado de Menores deu-me um cartão para que eu fosse procurar um amigo dele na Rádio Guanabara, Jorge de Matos, dono do Café Globo. Eu fui à Rádio Guanabara e, por coincidência, lá estava se realizando um concurso de locutores, do qual participavam, naquele tempo, uns 300 candidatos [...]. Fui o primeiro colocado nesse concurso e assim fui admitido como locutor (SILVA, 1972, p. 28-9).

Em relato a Silva (1972), Silvio afirmou que, o trabalho como camelô era muito mais rentável, o que fez com que sua carreira na Guanabara durasse apenas um mês. O então adolescente de 14 anos voltou para as ruas, onde vendia bonecas que dançavam,

\footnotetext{
${ }^{3}$ Este apelido é recorrentemente associado ao apresentador por causa do sucesso do "Baú da Felicidade", empresa de sua propriedade que consagrou seu êxito nos negócios, também intimamente atrelado ao êxito midiático, e vice-versa. Desde a década de 1950 até 2007, o Baú caracterizou-se pela venda a prazo de mercadorias que, após o pagamento de um carnê, eram retiradas em lojas físicas. Os fregueses que estivessem em dia com as mensalidades concorriam a diversos prêmios nos programas de Silvio Santos. A empresa passou a apostar em vendas a crediário e, em 2011, foi vendida. Em 2015, a marca foi retomada com a mesma dinâmica dos carnês, porém, trabalhando apenas com o comércio de cosméticos da Jequiti, outra empresa de Silvio (SILVA, 1972; MORGADO, 2017).
} 
canetas que não acabavam, anéis e remédio para calos. Trabalhava apenas 45 minutos por dia - o tempo que o guarda levava para almoçar - e ganhava muito mais do que recebia pelas quase cinco horas de serviço na rádio. No tempo que sobrava, aproveitava para comparecer a programas de auditório como os de Heber de Boscoli, com Yara Salles e Lamartine Babo, além de acompanhar as emissões de Cesar de Alencar. Estão aí as principais referências que mais influenciariam seu estilo, como ele rememora:

O Heber dizia: "Quem é que está com um sapato da Cedofeita no pé?". Aí todo mundo respondia: "Eu, eu, eu!". "Quem é que trouxe talãozinho?". "Eu, eu, eu!". Então, aquele bate-papo que o Heber de Boscoli tinha com o auditório é praticamente o bate-papo que hoje eu tenho com o auditório e aquela maneira como o César de Alencar falava é praticamente a maneira como eu falo hoje (SILVA, 1972, p. 31-2).

Em determinado momento, Silvio foi servir ao exército como paraquedista e, para evitar problemas com os superiores, abdicou do serviço de camelô. Foi o ponto de partida para que ele voltasse de vez para o meio, agora na rádio Mauá, onde trabalhava com Silveira Lima aos domingos, sem receber nada em troca (SILVA, 1972):

Não ganhava nada, mas fazia uma coisa que me agradava e que, em última instância, me realizava. Era uma atividade condigna com a minha condição de pára-quedista do Exército. Com a vivência que mantive, então, com locutores, artistas, animadores, diretores da Rádio Mauá, passei a encarar a profissão de radialista sob outro aspecto, o da seriedade e o da nobreza. Assim, quando saí do Exército, já não podia mais voltar para a avenida Rio Branco para vender quinquilharias. Já estava bem encaminhado dentro do rádio (SILVA, 1972, p. 34).

Posteriormente, com a mudança de Silveira Lima para a rádio Tupi, Silvio o acompanhou e passou a dividir seu tempo entre os trabalhos de locutor, figurante de televisão e vendedor em escritórios, obras e repartições. Ao ser convidado para assumir um programa próprio na rádio Continental em Niterói, das $22 \mathrm{~h}$ à meia noite, Silvio aceitou a proposta. Seria mais uma oportunidade de negócios, já que ele investiu em um sistema de alto falantes na barca que o conduzia até o Rio de Janeiro todas as noites (SILVA, 1972).

O negócio prosperou tanto que pouco depois de um ano na rádio, ele pediu demissão e dedicou-se exclusivamente aos serviços da barca, que compreendia a venda de bebidas, anúncios comerciais, folhetos de jogos e sorteios de brindes. Contudo, a barca teve um acidente e, enquanto estava parada para ser consertada, Silvio foi a São Paulo conhecer a cidade. O que era para ser apenas um passeio acabou durando mais 
tempo: ele fez um teste de locutor na Rádio Nacional, de São Paulo, ${ }^{4}$ e foi selecionado, tendo se dedicado concomitantemente a outras atividades, como um bar, animação de shows em circos, venda de anúncios e de uma revista de passatempos, até ser chamado por Manoel de Nóbrega para trabalhar em seu programa. Na nova cidade, ele participou dos programas Cadeira de Barbeiro e Praça da Alegria, ambos comandados por Nóbrega (SILVA, 1972).

Em determinada fase, além do trabalho no rádio, Silvio ainda fez locução em comícios e viajou com a Caravana do peru que fala, com artistas populares. Em 1960, para promover o Baú da Felicidade, lançou na TV Paulista o programa Vamos brincar de forca. Em 1963, estreava o Programa Silvio Santos, um dos mais longevos da história da televisão (SILVA, 1972).

Fernando Morgado (2011) ressalta que a popularização da televisão levou a transformações no rádio, que passou a apostar em uma relação mais intimista entre os comunicadores e seus ouvintes, agora chamados de "amigos", em detrimento dos auditórios. Nesse período, a Rádio Nacional, de São Paulo e a TV Paulista foram adquiridas pelas Organizações Globo, que imprimiram nas emissoras paulistanas a fórmula que vinha obtendo êxito em terras cariocas. Assim, naquela que viria a se tornar a nova Rádio Globo, de São Paulo, os programas priorizavam o carisma pessoal dos seus apresentadores - dentre eles Silvio Santos, que encabeçou um programa diário com seu nome.

Na Rua das Palmeiras - onde a sede paulistana do Sistema Globo de Rádio permanece até hoje - era comum ver o apresentador dividindo-se no acompanhamento das suas produções no rádio e na TV. O objetivo era transportar o clima do auditório dominical para o radinho das donas-de-casa - público principal da emissora neste horário. Para isso, muitas vinhetas cantadas e aplausos eram inseridos para dar um tom festivo ao programa (MORGADO, 2011, não paginado).

Silvio permaneceu na Rádio Nacional, de São Paulo até 1976, já que em 1977 adquiriu 50\% das ações da Rede Record (que abrangia a TV, Rádio Record e FM Record). Maria Celeste Mira (1994) destaca que, na Record, ele passou a adaptar versões de quadros que já faziam sucesso na televisão, como Viva o samba, Qual é a música? e Quem sabe mais, o homem ou a mulher? Com os esforços voltados para a implantação do canal de televisão a partir de 1976 , a carreira de Silvio Santos como

\footnotetext{
${ }^{4}$ Não confundir com a consagrada Rádio Nacional do Rio de Janeiro; a emissora de São Paulo nada tinha a ver com a homônima, pois pertencia às Organizações Victor Costa.
} 
comunicador de rádio foi interrompida e, em 1989, a Rede Record foi vendida para Edir Macedo.

Outra fonte de documentos a respeito da história de Silvio Santos no rádio são as revistas da época. Os poucos registros encontrados na internet são excertos de publicações antigas sobre o rádio, TV e artistas populares, como Ilusão, Melodias, Contigo! e Sétimo Céu, por exemplo. Contudo, além de serem raros, esses achados fazem poucas referências à carreira do animador no meio radiofônico, limitando-se a citar a atividade ou, no máximo, elogiá-la como mais um reflexo da "vocação irreprimível" de comunicar que ele teria:

Silvio Santos é o animador mais claro e objetivo da tevê e rádio brasileiros. Ele mesmo diz: "A minha meta fundamental é conquistar o maior número possível de ouvintes, por isso falo o vocabulário do povo, faço os programas que ele quer". Desta forma, tornou-se o animador mais ouvido e comentado do Brasil (CAMINHA, 1969, p. 23-4).

Nessas revistas, é possível perceber os primórdios de uma estratégia de "endeusamento" de Silvio que se desdobra nos dias atuais. As habilidades expressivas do apresentador são colocadas como algo divino, um dom dado por Deus. Discursivamente, a exaltação ao mito é feita por meio de fotografias que o mostram sorridente, gesticulando e brincando, além de uma semântica altamente positiva, com o uso de termos como "brilhante", "querido", "solerte" etc. Assim, constrói-se uma história mitológica que apaga qualquer tipo de conflito, opacidade ou tensão, priorizando superlativos positivos, em detrimento de uma precisão necessária para fins de uma reconstituição histórica coerente. Quando se lê a biografia de Silvio Santos, ficam evidentes suas conquistas, seus feitos e realizações, mas nem sempre é esclarecido como o empresário chegou até esses fins; elogios ficam em primeiro lugar, relegando a segundo plano detalhes, datas e informações mais completas.

Indo além do que se diz sobre a passagem de Silvio Santos pelo(as) rádio(s), nada melhor do que entrar em contato com os próprios programas. Contudo, a tarefa é dificultada em enorme medida devido à falta de informações disponíveis principalmente pela ausência de programas completos para consulta -, pelo menos em um primeiro momento da pesquisa. Por isso, nossa reflexão tem como base, principalmente, a análise seminal de Maria Immacolata Vassallo de Lopes na dissertação de mestrado intitulada $O$ rádio dos pobres: estudo sobre comunicação de massa, ideologia e marginalidade social (1982). 
Se não dispomos de programas completos para serem ouvidos e, tampouco, numerosos trechos dos programas, a minuciosa descrição de Lopes (1982) é preciosa para percebermos como se estruturava o programa de Silvio Santos. Isso porque, em seu trabalho, a autora aborda o consumo de programas radiofônicos populares pelas classes subalternas, tomando como objeto empírico as atrações de Gil Gomes (policial), Zé Bettio (musical) e Silvio Santos (variedades), este último merecedor de mais detalhamentos a seguir, conforme os objetivos do artigo. Contamos ainda com áudios de apoio encontrados no Youtube $e^{5}$ e em sites específicos sobre história do rádio, que trazem trechos de programas e nos ajudam a visualizar aquilo que foi analisado por Lopes (1982).

\section{Rastros e indícios do Programa Silvio Santos}

Cabe aqui fazer uma delimitação: a fase do Programa Silvio Santos cujas edições foram analisadas por Lopes (1982) concentra-se no ano de 1980 (cinco edições entre setembro e novembro), quando eram transmitidos diariamente, das $9 \mathrm{~h} 30$ às $10 \mathrm{~h} 30$ na Rádio Record. Nessa época, o apresentador já gozava de expressiva popularidade na televisão, pois já havia conseguido a concessão do canal 11 no Rio de Janeiro quatro anos antes, criando a TVS Rio, que, em 1981, viria a integrar o Sistema Brasileiro de Televisão - o SBT tal como conhecemos hoje. Nesse contexto, a Rádio Record tinha uma linha de programação voltada para um perfil popular e um mercado até então ignorado: o "mercado marginal". A especialização da audiência fez com que ela se tornasse a emissora mais ouvida na época da realização da pesquisa de Lopes (1982).

Sua linha de programação baseada na "filosofia povão" é reforçada com a emissão, a partir de 1977, do Programa Silvio Santos. Em 1978, Silvio Santos contrata Barros de Alencar, disc-jockey, líder de audiência no gênero musical popular; em 1979 contrata Ely Correa, de iguais características, e Jacinto Figueira Jr, "o homem do sapato branco". Nesse mesmo ano, com grande campanha publicitária, leva para a Rádio Record, Gil Gomes, "a maior audiência do país". Portanto, na convergência do gênero sertanejo, já anteriormente estabelecido na emissora, com os gêneros musical, popular, variedades e policial, constitui-se a programação base da Rádio Record; aquela expressa por uma "filosofia povão, destinada a levar o que é característico de São Paulo para todo o Brasil" (LOPES, 1982, p.120$1)$.

\footnotetext{
${ }^{5}$ Os áudios disponíveis no Youtube foram reunidos pelo autor do presente artigo em uma playlist que pode ser acessada pelo link disponível em: <https://www.youtube.com/playlist?list=PLNJFxC_zccts3EUSrBi2C8f2rTmpFocY>. Acesso em: 14 fev. 2017.
} 
Os dados trazidos pela autora indicam que a programação de variedades era o segundo gênero mais expressivo do rádio, presente no horário nobre de quase todas as emissoras (daquelas consideradas populares ou não). Lopes (1982) classificou o programa de Silvio na categoria "variedades" por localizá-lo no conjunto das atrações que eram dirigidas ao público feminino e estruturadas como revista de variedades. Os temas eram, então, bem diversificados, divididos em seções como culinária, beleza, administração do lar, horóscopo, saúde e bem estar, moda etc., conteúdo que, na visão da pesquisadora, contribuiria para reforçar padrões de comportamento, valores e papéis da mulher na sociedade. A começar pelas vinhetas, cantadas predominantemente por vozes femininas, que entoavam em timbres doces e agudos as mais variadas mensagens. Tais vinhetas teriam a função de representar a participação das ouvintes, já que, protagonizadas por mulheres, fariam as vezes das "colegas de trabalho" presentes no auditório do programa de Silvio na televisão.

Os quadros do programa, embora tenham sido enumerados por Lopes (1982), dizem respeito ao conteúdo disperso em cada edição (Quadro 1), não sendo tão bem separados e fechados, na prática ${ }^{6}$.

Quadro 1 - Quadros do Programa Silvio Santos na Rádio Record, em 1980.

\begin{tabular}{|l|l|}
\hline Vinheta de abertura & A tradicional música "Silvio Santos vem aí" \\
\hline Abertura & $\begin{array}{l}\text { Silvio se apresenta alegremente para as faixas de público } \\
\text { que visa atingir, sob a categoria do trabalho que executam } \\
\text { (donas de casa, caminhoneiros, taxistas, empregadas } \\
\text { domésticas). São as mulheres de baixa renda as principais } \\
\text { destinatárias do programa, e por isso os conteúdos são em } \\
\text { grande parte direcionados a elas. }\end{array}$ \\
\hline Oração & $\begin{array}{l}\text { Silvio faz um momento de reflexão espiritual seguido por } \\
\text { uma música de origem religiosa. }\end{array}$ \\
\hline Comerciais & $\begin{array}{l}\text { Silvio dá lugar a um locutor comercial que anuncia até 20 } \\
\text { comerciais, em sua maioria de empresas do Grupo Silvio } \\
\text { Santos. Ao vivo, os merchandisings são precedidos por } \\
\text { vinhetas musicais e anunciam medicamentos, artigos de } \\
\text { consumo e redes de lojas populares. }\end{array}$ \\
\hline Concurso & $\begin{array}{l}\text { Sorteios promovidos pelo próprio Silvio com o patrocínio } \\
\text { do Baú da Felicidade. }\end{array}$ \\
\hline Horóscopo & $\begin{array}{l}\text { Previsões astrológicas feitas por Zora Yonara que associa os } \\
\text { signos a celebridades e prescreve comportamentos. }\end{array}$ \\
\hline Consulta sentimental & $\begin{array}{l}\text { Prolongamento do quadro de horóscopo, aconselha ouvintes } \\
\text { com problemas de ordem afetiva e sentimental. Zora Yonara }\end{array}$ \\
\hline
\end{tabular}

\footnotetext{
${ }^{6}$ É preciso destacar que essas características dizem respeito às edições compreendidas no corpus de pesquisa da autora, podendo haver desvios em relação à totalidade dos programas. Esse é apenas um recorte que dá uma ideia de como se estruturava a atração radiofônica de Silvio Santos no início da década de 1980.
} 


\begin{tabular}{|l|l|}
\hline & participa. \\
\hline Fofocas & $\begin{array}{l}\text { Silvio assume o lugar de ouvinte, e pergunta para Nelson } \\
\text { Rubens as novidades sobre personalidades da TV e da } \\
\text { música, dirigindo e organizando o discurso do "repórter de } \\
\text { fofoca". }\end{array}$ \\
\hline Informação da hora & Silvio informa as horas depois de uma vinheta. \\
\hline Músicas & $\begin{array}{l}\text { São tocadas duas músicas, exclusivamente de Roberto } \\
\text { Carlos. }\end{array}$ \\
\hline $\begin{array}{l}\text { Vinhetas/fundos } \\
\text { musicais }\end{array}$ & $\begin{array}{l}\text { As vinhetas mantêm o ritmo e clima alegre do programa, } \\
\text { com frases musicais entoadas por vozes femininas. Os } \\
\text { fundos instrumentais ambientam os momentos sentimentais } \\
\text { da leitura de cartas. }\end{array}$ \\
\hline Gargalhadas & $\begin{array}{l}\text { Recurso largamente utilizado para expressar o ideal de } \\
\text { felicidade propalado pelo apresentador. Lopes (1982) } \\
\text { destaca que em uma edição foram contadas 46 gargalhadas, } \\
\text { sendo 34 emitidas por Silvio. }\end{array}$ \\
\hline Boletim noticioso & $\begin{array}{l}\text { A cada hora, é inserido o boletim jornalístico Record em } \\
\text { Notícias, independente do programa. }\end{array}$ \\
\hline
\end{tabular}

Fonte: Elaborado pelo autor com base em Lopes (1982).

Nos trechos que encontramos na internet, foi possível localizar exemplos de alguns quadros citados por Lopes (1982). É o caso de Consulta sentimental, no qual Silvio aconselha uma ouvinte. O áudio segue e ouve-se ainda: a tradicional abertura do programa; uma vinheta de "bom dia" cantada por vozes de mulheres; uma oração para "respeitosamente agradecer a Deus ter ele permitido o café dessa manhã e, por conseguinte mais um dia de vida", e a música de origem judaico-cristã "Shalom" (CANAL..., 2014).

Em outro áudio (FERAS..., 2014) um quadro chamado Falando francamente (não evidenciado por Lopes), Silvio apresenta uma espécie de debate popular sobre as previsões do fim do mundo, feitas por um astrólogo para 1982, e a expectativa de que a pobreza absoluta atingisse 600 milhões de pessoas até o ano 2000, segundo um relatório do Banco Mundial. Comentam as notícias três participantes no papel de especialistas, um deles cuja voz parece ser a de Décio Piccinini. Num tom mais sério, diferente do usual, Silvio também comenta, mostra-se assustado com as informações, e age como uma espécie de mediador dos debatedores, tentando recapitular e obter explicações deles. Pode ser ouvido também o quadro Fofocas, com Nelson Rubens?.

Os temas mais recorrentes nas edições analisadas por Lopes (1982) foram sucesso, sorte, sexualidade e felicidade, podendo ser abrigados no discurso mítico da "fama e fortuna", nos sentidos de sorte e riqueza que, como já argumentamos, são bases

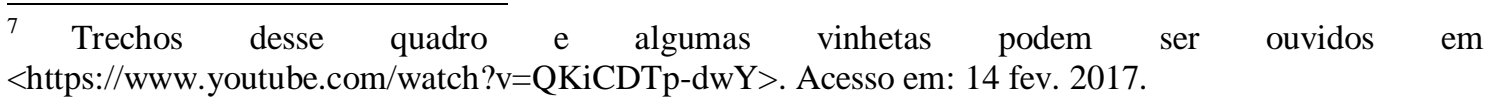


constitutivas do arcabouço simbólico de Silvio Santos. O programa ainda cumpriria a importante função de promover a atração televisiva e os demais negócios de Silvio.

Em seu trabalho, Lopes (1982) considerou Silvio Santos como "olimpiano", ou seja, um herói-modelo ao mesmo tempo humano e divino que saberia conciliar habilmente a vida cotidiana e a vida espetacularizada. Assim, Silvio se integraria perfeitamente ao discurso mítico evidente no programa, seja pelo fato de ele mesmo participar como personagem de algumas fofocas envolvendo as celebridades da época ou devido ao papel de narrador que exercia.

Na visão da autora, a relação que os(as) ouvintes estabeleciam com o Programa Silvio Santos era de projeção, já que a atração insistia em conteúdos e abordagens que mobilizavam o mito do urbanismo: o sucesso (ou a fama) e o enriquecimento (ou a fortuna). Como tais valores seriam irrealizáveis de forma concreta para o público popular do apresentador, caberia aos ouvintes engajarem-se em uma relação de evasão, projetando-se e imaginando um futuro de riquezas que somente os prêmios do Baú da Felicidade poderiam tornar possível. Ela ainda identificou o discurso de sorte e destino em outros quadros do programa, como os conselhos, o horóscopo e os exemplos da vida de sucesso dos artistas, por exemplo.

Os ouvintes alegaram que acompanhavam o programa pelas seguintes razões: o apresentador, a diversão proporcionada, a informação transmitida e os prêmios concedidos. A voz de Silvio Santos também foi um aspecto bastante destacado pelos receptores, que a qualificaram como alegre, comunicativa, boa, bonita, agradável, confiante, espontânea e natural. Com a função emotiva exercida pela voz entusiasmada e natural, o efeito de sentido se caracterizaria por um alto nível de envolvimento psicológico dos ouvintes (LOPES, 1982).

\section{O que há de Programa Silvio Santos (1980) no Programa Silvio Santos (2016)?}

É interessante observar que, das características apontadas por Lopes (1982), muitas permanecem praticamente inalteradas no programa televisivo de Silvio Santos. Consolidando o estilo comunicativo do apresentador, tais elementos conferem à atração um status de tradição a ser preservada, o que diferencia o programa de outros. Se a televisão caracteriza-se pelas constantes mudanças das mais variadas ordens, o Programa Silvio Santos (PSS) seria, então, um dos poucos a tentar manter estratégias que dão certo desde os tempos de rádio. 
A começar pela música de abertura - a consagrada Silvio Santos vem aí, composta por Archimedes Messina -, o clima de conservação do passado abre o programa quase da mesma forma desde 1965, quando a marchinha foi produzida sob encomenda para o mesmo programa. A canção Shalom, que encerrava o momento de oração comandado por Silvio, hoje pode ser ouvida eventualmente nas aberturas dos programas de televisão, mas numa versão sem insinuação religiosa por parte do roteiro ou da fala do apresentador. Mesmo assim, ela evoca um imaginário religioso, já que faz parte do cancioneiro judaico tradicional e uma de suas variações pode ser ouvida até mesmo em ritos católicos, por exemplo.

Essas escolhas contribuem para um apelo à memória construída sobre e em torno do referido programa, que, entre rádio e televisão, já soma 53 anos no ar (embora com algumas interrupções). A atração está arraigada não apenas no imaginário da televisão no Brasil, como também nos vínculos nostálgicos estabelecidos com o ouvinte e/ou telespectador. Pensando a memória como uma construção do presente a partir do passado (HALBWACHS, 2006), podemos dizer que, a cada domingo, atualiza-se e rememora-se na televisão diversos traços dos programas que Silvio apresentava no rádio, descortinando lembranças coletivamente e reiterando o culto à figura do apresentador.

Ver o programa pode acionar lembranças e memórias da trajetória do público, fortalecendo os laços afetivos com Silvio e com o SBT; assistir ao "homem do baú" pode nos fazer lembrar de um tempo distante cronologicamente, mas muito próximo simbolicamente, cada vez mais vivo quando se entra em contato com as mesmas músicas, os mesmos quadros, o mesmo animador e as várias outras reminiscências de outrora.

Se o primeiro programa de Silvio Santos, Vamos brincar de forca, surgiu para promover o Baú da Felicidade, a mesma lógica comercial impera até hoje em suas atrações, como é o caso do PSS. Nos intervalos, pode-se assistir a publicidades de empresas pertencentes ao Grupo Silvio Santos, como a Jequiti Cosméticos, o Hotel Jequitimar, a Tele Sena e o próprio Baú, o que confirma as palavras do empresário: "Não, eu sempre me vi como produto, um produto meu. Sou um bom vendedor. Sou um vendedor que usa a eletrônica para vender seus produtos, artistas, programas" (BERGAMO, 2013). "Sou... Vendedor ambulante. Só que agora sou vendedor ambulante com alto-falante" (STYCER, 2014).

No universo mercadológico e simbólico de Silvio Santos, sorte e destino andam 
lado a lado; por isso, os concursos e sorteios estão fortemente presentes. Lopes (1982) já notava, há 34 anos, a prevalência do jogo no programa radiofônico, tendência que se mantém atual, se olharmos para a $\operatorname{lista}^{8}$ de segmentos do conteúdo que compõe o programa de TV: 22 quadros são relativos a concursos, sorteios e demais tipos de jogos, todos premiados em dinheiro. Isso quer dizer que, desde os primórdios de sua atividade midiática, há uma tentativa de atribuição da sorte dos jogadores a Silvio e a suas empresas, que prometem a realização de sonhos materiais por meio de seus produtos, principalmente a partir da participação em jogos. A premissa é a de que é possível obter o mesmo sucesso do apresentador, desde que o consumidor participe das oportunidades dadas por ele nos mais variados game shows, reality shows e sorteios.

Os estudos sobre o programa de Silvio Santos na TV (MIRA, 1994; SOUSA, 2009; ALVARADO, 1995; MONTAÑO, 2007) vêm reforçar, em grande medida, a constatação de Lopes (1982) em relação às emissões de rádio do Programa Silvio Santos: ainda hoje, a interação que o público tem com o programa e o SBT em si apresenta tons de projeção e identificação. Identificação com o Silvio homem, pai, excamelô, herói cômico, e projeção com base no Silvio milionário, apresentador, patrão, santo. Tais atribuições, tão interligadas e ao mesmo tempo tão diversas, constituem-no como um modelo de realização, um modelo de vida (MARTINS, 2016).

Se em suas análises Lopes (1982) detectou que as emissões se baseavam quase totalmente na figura do próprio Silvio, sendo que esporadicamente ele dividia suas funções com outros profissionais (astróloga, "repórter de fofoca"), as pesquisas sobre suas emissões televisivas evidenciam que a mesma estratégia pode ser vista mais recentemente. Ana Alvarado (1995) denominou "silviocentrismo" a onipresença do apresentador em seu programa, fenômeno que se dá principalmente a partir de uma linguagem verbal de persuasão autoritária revestida de lúdica. Haveria uma ilusão de igualdade entre o animador e o ouvinte porque, na verdade, o contato e a proximidade tão celebrados seriam apenas uma simulação com vistas a gerar o efeito de fidelização.

\section{Conclusão}

Mais do que propor conclusões, nesta seção sistematizam-se as principais questões e inquietações que emergiram do objeto em estudo. Primeiramente, foi interessante perceber que as características expostas por Maria Immacolata Vassallo de

\footnotetext{
8 Levantamento feito segundo dados disponíveis no site http://www.sbt.com.br/programasilviosantos/quadros/quadros_todos.asp. Acesso em: 12 mar. 2016.
} 
Lopes nos longínquos 1980 ainda permanecem praticamente inalteradas, o que mostra a construção e consolidação não apenas de um "estilo Silvio Santos", bem como de uma identidade que ele soube emprestar às suas empresas, especialmente o SBT.

Saltam aos olhos e aos ouvidos as permanências que podem ser notadas quando se faz um paralelo entre um programa de Silvio no rádio da década de 1980 e o cenário televisivo atual. Isso porque vários profissionais citados por Lopes (1982) ainda se encontram em profícua atividade: Nelson Rubens continua fazendo fofocas, Zora Yonara ainda faz suas previsões de horóscopo, Décio Piccinini ainda participa dos programas de Silvio etc. Isso mostra o quão recente é a história do rádio e da televisão no Brasil e ainda o quanto recorremos a fórmulas e formatos antigos, fazendo (con)fundir as matrizes do moderno e do popular.

$\mathrm{Na}$ reconstituição que outros autores fazem sobre a trajetória de Silvio Santos, o tempo que ele se dedicou profissionalmente ao rádio aparece mais como uma espécie de "trampolim" para que chegasse à TV, como se esse meio fosse mais importante e só ele possibilitasse a consagração e o sucesso. Portanto, o rádio é visto como uma porta de entrada para a TV, e encarado mais como um meio técnico do que como uma fase que moldou expressivamente a linguagem e o formato de Silvio Santos. Basta fazermos um paralelo sobre as emissões radiofônicas e as edições televisivas atuais para percebermos o quanto as linguagens, estilos e formatos de rádio e televisão são devedores uns dos outros.

Dada a cobertura altamente enviesada e focada apenas nos aspectos positivos da trajetória radiofônica de Silvio Santos encontrada nas fontes biográficas do apresentador (livros, biografias, revistas sobre sua história de vida), acreditamos que os próximos estudos sobre o tema devem se concentrar nos programas em si. Entretanto, se temos aí uma possibilidade de pesquisa, coloca-se também uma dificuldade a ser vencida, já que o acesso a arquivos dos programas é limitado.

Mesmo assim, acreditamos que a opção pela materialidade do discurso de Silvio Santos em sua produção no rádio acena como um caminho mais próximo da forma e do conteúdo que pode possibilitar um entendimento mais completo não só da contribuição do apresentador em questão, bem como da realidade do rádio da época em que ele se inseria. Embora seja muito admirado, Silvio Santos ainda recebe poucos investimentos de estudos que o considerem um fenômeno comunicacional, principalmente no que se refere ao seu lado locutor de rádio. Por isso, mais análises são necessárias para 
compreendê-lo em sua complexidade.

\section{REFERÊNCIA BIBLIOGRÁFICA}

ALVARADO, Ana Bertha. Entre a autoridade e as gargalhadas: uma leitura exploratória sobre a construção da imagem televisiva de Silvio Santos. 1995. $121 \mathrm{f}$. Dissertação (Mestrado em Comunicação Social) - Programa de Pós-Graduação em Comunicação Social, Universidade Metodista, São Paulo, 1995.

BERGAMO, Monica. Em entrevista exclusiva, Silvio Santos diz que a TV Record joga dinheiro fora. Folha de S. Paulo, 23 jun. 2013. Disponível em: <http://www1.folha.uol.com.br/colunas/monicabergamo/2013/06/1299336-ementreivstaexclusiva-silvio-santos-diz-que-a-tv-record-joga-dinheiro-fora.shtml $>$. Acesso em: 8 mar. 2016.

CAMINHA, Paulo. Silvio Santos, o sorriso que vale milhões. Sétimo Céu, no 161 , p. 23-24, ago. 1969.

CANAL Ibs. 7 Trecho do programa Silvio Santos na Rádio Nacional360p H 264 AAC. Youtube, 25 mar. 2014. Disponível em: <https://www.youtube.com/watch?v=_NTz3qcMcTg>. Acesso em: 14 fev. 2017.

CHIARI, Tatiana. et al. Silvio Santos, a história de um vencedor. São Paulo: Abril, 2001.

FERAS do Rádio. Falando francamente: Silvio Santos no rádio em 1981. Youtube, 26 fev. 2014. Disponível em: 〈https://www.youtube.com/watch?v=Vgk5LPJm4Ec〉. Acesso em: 14 fev. 2017.

HALBWACHS, Maurice. A memória coletiva. São Paulo: Centauro, 2006.

LOPES, Maria Immacolata Vassalo de. $O$ rádio dos pobres: estudo sobre comunicação de massa, ideologia e marginalidade social. 1982. 276 f. Dissertação (Mestrado em Ciências da Comunicação) - Programa de Pós-Graduação em Ciências da Comunicação, Universidade de São Paulo, São Paulo, 1982.

MARTINS, Rafael Barbosa Fialho. A TV mais feliz do Brasil: a proposta de interação do SBT com a audiência. 2016. 188 f. Dissertação (Mestrado em Comunicação Social) - Programa Pós-Graduação em Comunicação Social, Universidade Federal de Minas Gerais, Belo Horizonte, 2016. Disponível em: < http://hdl.handle.net/1843/BUBDA95FET>. Acesso em: 25 nov. 2017.

MIRA, Maria Celeste. Circo eletrônico: Silvio Santos e o SBT. São Paulo: Loyola, 1994.

MONTAÑO, Sonia. A TV jogo no SBT. 2007. 164 f. Dissertação (Mestrado em Comunicação Social) - Programa Pós-Graduação em Comunicação Social, Universidade do Vale do Rio dos Sinos, São Leopoldo, 2007. Disponível em: <http://www.repositorio.jesuita.org.br/handle/UNISINOS/2619>. Acesso em: 14 fev. 2017 
MOREIRA, Sonia Virgínia. Análise documental como método e como técnica. In: DUARTE, Jorge; BARROS, Antonio (Org.). Métodos e técnicas de pesquisa em Comunicação. São Paulo: Atlas, 2004. p. 51-61.

MORGADO, Fernando. Silvio Santos - a trajetória do mito. São Paulo: Matrix, 2017.

Silvio Santos no rádio. Site do Fernando Morgado. 2011. Disponível em <http://fernandomorgado.com.br/artigo/silvio-santos-no-radio>. Acesso em: 2 mar. 2016.

SILVA, Arlindo. A fantástica história de Silvio Santos. São Paulo: Editora do Brasil, 2000.

A vida espetacular de Silvio Santos. Rio de Janeiro: L'Oren, 1972.

SOUSA, Silvia. Silvio Santos vem aí - programas de auditório do SBT numa perspectiva semiótica. 2009. 196 f. Tese (Doutorado em Estudos Linguísticos) Programa de Pós-Graduação em Letras, Universidade Federal Fluminense, Niterói, 2009.

STYCER, Mauricio. Silvio Santos renova a arte de vender a ilusão do dinheiro fácil na TV. 2011. Blog Mauricio Stycer, 2011. Disponível em: $<$ http://mauriciostycer.blogosfera.uol.com.br/2011/09/22/silvio-santos-renova-a-arte-devender-a-ilusao-do-dinheiro-facil-na-tv/>. Acesso em: 2 mar. 2016.

\footnotetext{
Mauricio

Submetido em 01.08.2016

Aceito em 27.08.2017
}

Silvio Santos: "Sou um vendedor ambulante com alto-falante". 2014. Blog do

<http://mauriciostycer.blogosfera.uol.com.br/2014/10/31/silvio-santos-sou-um-

em: vendedor-ambulante-com-alto-falante/>. Acesso em: 15 mar. 2016. 